\title{
Erratum to: OpenGeoSys Tutorial
}

\section{Erratum to:}

E. Jang et al., OpenGeoSys Tutorial, SpringerBriefs in Earth System Sciences, https://doi.org/10.1007/978-3-319-67153-6

The original version of the book was inadvertently published without incorporating the corrections in Appendix A coding, which has been carried out now.

The updated online version of this book can be found at https://doi.org/10.1007/978-3-319-67153-6 